Selected Papers of Ernst Georg Pringsheim

Edited and with a preface by Prof. C. B. van Niel. Pp. ix + 331. (Published for the Institute of Microbiology. Distributed by Rutgers University Press, New Brunswick, New Jersey, 1963.) 6.50 dollars.

$\mathrm{M}$ ICROBIOLOGY is now in a transitional stage in which the ideas of the older microbiologists, based as they wcre on morphology and simple physiology, have given way to those of the biochemist, the geneticist, and the statistician. Pringshoim bolongs to the old school, and to read those collected papers is like turning back from the pages of a modern biology to a treatise on old-fashioned natural history. Horo aro arguments and discussions based almost entirely on morphology, and there is a wonderful sense of simplicity about all the micro-organisms discussed in these papers. That they are borderline forms between the blue-green algae and the bacteria is not disputed, but there is a remarkable-some might think commendable-lack of evidence of the kind we now expect and demand of our taxonomists.

This is a group of micro-organisms about which most of us know little or nothing, and they are described by a master of technique who has had tho patience and pertinacity to make of them a most detailed study; here he tells us in simple terms what he has learnt in this work of a lifetime. They are probably not economically important organisms, thoy do not cause infections or poison food, but they are the happy hunting ground of an almost extinct kind of naturalist-microbiologist. This book is refreshing, for it shows how far we have come in the past few decades; it is stimulating, for it shows how right we are to question all the convictions of the classical taxonomists.

These papers show what has been done by good tochnique and careful observation; they should serve as object lessons to microbiologists to renew acquaintance with the light microscope and the simpler tools of their trade. With the advantage of hindsight we may be tempted to judge Pringsheim's opinions as those of a dogmatic teachor upbraiding the enquiring and unbelieving pupil. $\mathrm{H}_{\Theta}$ is impatient with Buchanan and intolerant of opinions such as Pijper's on the mechanism of bacterial motility, but the simplicity of the arguments is like manna to the genetically and computer-sotted mind of the modern taxonomist.

S. T. CowaN

\section{The Formation of Wood in Forest Trees}

The Second Symposium held under the Auspices of the Maria Moors Cabot Foundation for Botanical Research, Harvard Forest, April 1963. Edited by Martin H. Zimmermann. Pp. xv +562 . (Now York and London: Academic Press, 1964.) 114s. 6d.

"r THE Physiology of Forest Trees" was the theme of the first Cabot Foundation symposium, and the second, held six years later in 1963, took as its topic "The Formation of Wood in Forest Trees", thus continuing the general subject of fundamental problems of tree growth. The papers and edited discussions are now available in this excellent publication.

In recent years, much research has gone into the various processes which are associated with the formation of wood and many of the results and some of the theories of this rather complicated subject have boen dealt with by the 28 contributors from North and South America, Europe and Australasia. The papers are grouped into four parts. Part $l$ is concerned with the cambium and its derivatives. Too often the cambium is treated in rather general terms, but it is evident that we need to know more about its rate of division during the growing season to prove or disprove certain theories associated with it. Phloem, one of its derivatives, becomes in its secondary state bark, but the characteristics of a particular bark are determined not only by the structure and develop- ment of the phloem but also by the structure of the periderm and by the timing, depth and frequency of its initiation in the bark. Advances in electron microscopy and photographic techniques have helped to provide new knowledge on the structure and formation of the cell wall; some excellent illustrations are provided in a comprehensive and detailed paper on this subject.

The complicated chemistry of the three main constituents of cell walls-cellulose, hemicellulose and ligninis dealt with in Part 2. This is followed by Part 3, which contains five papers associated with the translocation of photosynthetic products to the cambium. Much of the recent knowledge on this subject has been brought about by newly developed carbon-14 techniques. One such series of experiments shows that there is a complex of processes involved in the translocation of organic material from the site of assimilation to the place of utilization, but that the physiological activity of the latter is probably the main factor in controlling translocation. The final part embraces some of the internal and external factors controlling wood formation, and it is empha. sized more than once that more field experiments are required to elucidate the relationships which may exist between growth behaviour and environmental factors.

These papers will be welcomed by the various specialists in this complex subject, not only for their own worth and for points brought out in the associated discussions, but also for the lists of references. Editor and publisher have presented the material in a most commendable way.

C. J. TAYLOR

\section{Green Medicine}

The Soarch for Plants that Heal. By Margaret B. Kreig. Pp. $462+63$ photographs. (Chicago and Now York: Rand McNally and Company, 1964.) 5.95 dollars.

THE sub-title of this book, "The Search for Plants that Heal", roughly indicatos its content. It is written in a popular and somewhat dramatic style by a professional American woman journalist with a sciontific background -and also three young sons! The object of the book is to direct attention to the enormous amount of energy and money that is being applied in the United States, especially by the large drug firms, in attempting to produce new drugs from plants. Facts and figures quoted are likely to be an eye-opener for many readers, especially for those outside the United States. Some of the plants producing such well-known drugs as quinine and digitalis are also discussed.

There is much of interest in the book, such as the chapter on Mexican wild yams as sources of diosgenin, the chaptor on Rauwolfia for reserpine and the remarks on the amazing narcotic plants of the Americas used for centuries by Amerindians. The writer gives reasons for the belief that in the next quarter of a century our knowledge of the drug plants of the world will increase greatly and that there will be much activity in their investigation.

F. N. Howes

\section{Dissection of the Locust}

By Dr. Joan G. Thomas. Pp. 72. (London: H. F. and G. Witherby Ltd., 1963.) $8 s .6 d$.

YNTIL about twenty years ago, the advanced school pupil and university undergraduate were almost always introduced to insect anatomy by dissecting the cockroach. This insect was readily available and so also were accounts of its anatomy and instructions for its dissection. However, improved standards of hygiene have made the cockroach more difficult to obtain, and the establishment of many laboratory cultures of the migratory locust in Britain has provided an alternative, 